\title{
KAJIAN 14 PILLAR PADA TRAVEL AND TOURISM COMPETITIVENESS INDEX (TTCI) SEBAGAI INDIKATOR DAYA SAING PARIWISATA SUATU NEGARA
}

\author{
Yuviani Kusumawardhani \\ Sekolah Tinggi Pariwisata Bogor \\ kusumawardhaniyuvi@gmail.com
}

\begin{abstract}
The concept of competitiveness is undergoing a revolution. The revolution of competitiveness theory becomes a new paradigm. Initially, competitiveness theory discusses the ability of a company to survive in a dynamic market. The new paradigm regarding the theory of competitiveness that has become normal science is currently being defined as a concept of competitiveness between countries. One of the competitiveness of a country can be obtained from the tourism sector. Why tourism? Because tourism has developed into a major and mainstay industry in the world. The World Economic Forum (WEF) as an international institution issued a report measuring the travel and tourism competitiveness of its 136 member countries. The report in question is better known as the Travel and Tourism Competitiveness Index (TTCI), in which there are 14 pillars that are indicators of a country's competitiveness. This study uses a qualitative approach with a literature study method, which aims to examine the 14 pillars as an indicator of the competitiveness of a country's tourism. These indicators are actually quite good in describing the competitiveness of a country in travel and tourism, but in developing countries there are several indicators that are still difficult to achieve because development in certain sectors is still in the process of development and takes a long time to be assessed to reach the minimum value of the TTCI indicator. This has an impact on the assessment based on indicators on TTCI for developing countries that is not optimal.
\end{abstract}

Keywords: Competitiveness, TTCI, Tourism, Travel, Tourism Competitiveness

\begin{abstract}
ABSTRAK
Konsep daya saing mengalami sebuah revolusi. Revolusi teori daya saing menjadi sebuah paradigma baru. Mulanya, teori daya saing membahas mengenai kemampuan suatu perusahaan agar tetap bertahan dalam pasar yang dinamis. Paradigma baru mengenai teori daya saing yang menjadi normal science saat ini didefinisikan menjadi suatu konsep daya saing antar negara. Daya saing suatu negara dapat diperoleh dari salah satunya adalah sektor pariwisata. Mengapa pariwisata? Karena Pariwisata telah berkembang menjadi suatu industri besar dan andalan di dunia. World Economic Forum sebagai sebuah Lembaga internasional mengeluarkan sebuah report yang mengukur daya saing travel dan pariwisata dari 136 negara anggotanya. Laporan yang dimaksud lebih dikenal dengan Travel and Tourism Competitiveness Index (TTCI), yang didalamnya terdapat 14 pilar yang menjadi indikator daya saing suatu negara. Penelitian ini menggunakan pendekatan
\end{abstract}


kualitatif dengan metode studi kepustakaan, bertujuan untuk mengkaji 14 pilar tersebut sebagai indikator daya saing pariwisata suatu negara. Indikator-indikator ini sebenarnya sudah cukup baik dalam menggambarkan daya saing suatu negara pada travel dan pariwisata, namun pada negara berkembang terdapat beberapa indikator yang masih sulit untuk dicapai karena pembangunan di sektor tertentu yang masih dalam proses pembangunan dan membutuhkan waktu cukup lama untuk dapat dinilai setidaknya untuk mencapai nilai minimal indikator TTCI. Hal ini berdampak pada penilaian berdasarkan indikator-indikator pada TTCI untuk negara berkembang yang tidak maksimal.

Kata Kunci : Daya Saing, TTCI, Pariwisata, Travel, Daya Saing Pariwisata

\section{PENDAHULUAN}

Daya saing merupakan sebuah konsep perbandingan antara kemampuan dan kinerja perusahaan, sub-sektor atau negara untuk menjual dan memasok barang dan atau jasa yang diberikan pada pasar. Berdasarkan World Economic Forum, daya saing nasional adalah kemampuan perekonomian nasional untuk mencapai pertumbuhan ekonomi yang tinggi dan berkelanjutan. Daya saing ditentukan oleh keunggulan bersaing suatu perusahaan dan sangat bergantung pada tingkat sumber daya relatif yang dimilikinya atau biasa kita sebut keunggulan kompetitif (Porter 2001). Porter menjelaskan pentingnya daya saing karena tiga hal berikut: (1) mendorong produktivitas dan meningkatkan kemampuan mandiri, (2) dapat meningkatkan kapasitas ekonomi, baik dalam konteks regional ekonomi maupun kuantitas pelaku ekonomi sehingga pertumbuhan ekonomi meningkat, (3) kepercayaan bahwa mekanisme pasar lebih menciptakan efisiensi. Frinces (2011) mengatakan bahwa kenggulan berasal dari proses kerja yang dilakukan dengan kualitas yang baik dan konsep manajemen professional yang diiringi dengan kontribusi sumber daya terbaik seperti bahan baku, kepemimpinan, keuangan yang cukup, SDM dan dukungan dari teknologi yang canggih.

Berdasarkan teori daya saing, terdapat dua teori daya saing yaitu teori keunggulan komparatif dan keunggulan kompetitif yang digunakan sebagai indikator tingkat daya saing. Teori keunggulan komparatif menurut (Ricardo 2008) mengacu pada keunggulan yang dimiliki setiap daerah atau negara. Teori tersebut mengatakan bahwa apabila dua negara melakukan perdagangan suatu komoditi bagi komoditi yang memiliki keunggulan komparatif dan merupakan spesialisasi negara tersebut, maka negara-negara yang melakukan perdagangan akan mendapatkan keuntungan. Keunggulan komparatif suatu komoditi dalam konteks regional merupakan komoditi yang relatif lebih unggul dibandingkan komoditi yang dimiliki oleh daerah lainnya. Keunggulan tersebut dapat dilihat dari biaya kegiatan produksi yang relatif lebih rendah dibandingkan daerah lainnya. Ketika suatu daerah dapat mengetahui sektor mana yang memiliki keunggulan komparatif maka pemerintah sebagai penentu kebijakan dapat mengatur strategi daya saing guna menentukan arah pembangunan sektor tersebut. Keunggulan komparatif yang dimiliki suatu daerah muncul karena adanya faktor-faktor pembentuk, seperti kondisi alam yang sudah ada. Saat ini masyarakat sudah mengenal teknologi, sehingga dapat dikatakan bahwa masyarakat memiliki keterampilan khusus dan sudah tertanam mentalitas untuk melakukan pembangunan. 
Keunggulan kompetitif merupakan suatu keunggulan yang diciptakan terlebih dahulu untuk memilikinya, dengan kata lain keunggulan kompetitif adalah keunggulan yang dapat dikembangkan. Keunggulan kompetitif suatu komoditi merupakan hasil olahan yang terbentuk dari kinerja yang dimilikinya sehingga dapat lebih mengungguli komoditi sektor lainnya. Menurut Porter (1995), hal yang paling penting dalam pengukuran daya saing adalah produktivitas suatu industri baik dalam memproduksi barang maupun jasa. Produktivitas dapat meningkatkan pendapatan per kapita disusul dengan pertumbuhan ekonomi suatu negara. Porter (1995) mengemukakan pentingnya daya saing bagi sebuah industri karena dapat meningkatkan kapasitas ekonomi yang mampu meningkatkan pertumbuhan ekonomi dalam jangka panjang, menjadi stimulator peningkatan produktivitas dan kemampuan usaha mandiri, dan adanya kepercayaan bahwa mekanisme pasar dapat menimbulkan efisiensi.

Daya saing suatu negara dapat diperoleh dari salah satunya adalah sektor pariwisata. Mengapa pariwisata? Karena Pariwisata telah berkembang menjadi suatu industri besar dan andalan di dunia, hal ini ditandai dengan terus meningkatnya pendapatan yang dihasilkan oleh jumlah kunjungan wisatawan. Menurut Smith (1989); Sharpley (2000); dan Bui (2000) dalam Brokaj (2014), banyak negara berkembang mempromosikan pariwisatanya karena pariwisata berpotensi untuk menciptakan lapangan pekerjaan, meningkatkan pendapatan per kapita, dan meningkatkan devisa serta pendapatan pemerintah. Pariwisata berdampak terhadap perekonomian secara langsung maupun tidak langsung. Dampak secara langsung dapat dilihat dari tingkat belanja pariwisata, penambahan lapangan kerja, redistribusi pendapatan, dan penguatan neraca pembayaran. Sedangkan dampak tidak langsung dapat dilihat dari pegukuran dampaknya terhadap peningkatan pertumbuhan ekonomi. Dampak yang ditimbulkan pariwisata terhadap pertumbuhan ekonomi dalam jangka panjang di identifikasi melalui jalur yang berbeda, yaitu: (1) Pariwisata memiliki peran penting dalam pertumbuhan investasi pada infrastruktur baru dan meningkatkan persaingan antara perusahaan lokal dengan perusahaan asing; (2) Pariwisata menjadi stimulator pada industriindustri lainnya untuk berkemban; (3) Pariwisata merupakan penghasil devisa yang cukup besar, yang mana digunakan untuk membayar bahan impor untuk selanjutnya diproduksi menjadi barang layak jual; (4) Pariwisata menciptakan lapangan pekerjaan dan meningkatkan penyerapan tenaga kerja pada lapangan yang tersedia; (5) Pariwisata diyakini dapat memberikan eksploitasi postif dari skala ekonomi perusahan nasional; (6) Pariwisata menjadi faktor penting dalam transfer ilmu pengetahuan dan teknologi, stimulator pada riset dan pengembangan, dan akumulasi modal manusia (Nizar 2011).

Daya saing pariwisata juga perlu disiapkan untuk memenuhi standar internasional sehingga dapat lebih kompetitif. World Economic Forum adalah sebuah lembaga terpercaya yang berpusat di Geneva, Swiss. Lembaga ini mengeluarkan sebuah laporan yang dikenal dengan Travel and Tourism Competitiveness Index dan menjadi referensi bagi 136 negara di dunia untuk memeringkat negara-negara yang memiliki daya saing pariwisata dengan kriteria yang jelas. Terdapat 14 pilar yang dikalibrasi dengan standar yang sama oleh Travel \& Tourism Competitiveness Index (TTCI). Pilar-pilar yang dimaksud ini diantaranya adalah business environment, safety and security, health and hygiene, human resource and labour market, ICT readiness, prioritization of travel and 
tourism, international openness, price competitiveness, environmental sustainability, air transport infrastructure, ground and port infrastructure, tourist service infrastructure, natural resources, dan cultural resources and business travel.

Indikator-indikator diatas selama ini digunakan dalam laporan TTCI agar negara-negara dapat mengetahui sudah seberapa jauh negaranya memiliki daya saing pariwisata, selain itu mereka juga dapat mengetahui faktor mana yang menjadi titik lemah daya saing pariwisata sehingga mereka dapat segera memperbaikinya. Namun apakah ke-14 pilar sudah cukup mewakili daya saing travel dan pariwisata suatu negara? Hal inilah yang melandasi penelitian ini, untuk mengkaji lebih jauh ke-14 pilar yang terdapat pada TTCI sebagai indikator daya saing travel dan pariwisata bagi suatu negara.

\section{METODOLOGI}

Penelitian dilakukan dengan menggunakan metode kualitatif yaitu studi kepustakaan. Studi kepustakaan adalah sebuah metode untuk menganalisis sebuah teks atau wacana untuk mengkaji hasil pemikiran dan penelitian seorang peneliti (Ibrahim 2015). Penelitian kepustakaan selalu identik dengan kegiatan analisis sebuah teks atau wacana. Analisis adalah penyelidikan terhadap suatu peristiwa, baik berupa perbuatan atau tulisan yang diteliti untuk mendapatkan fakta yang tepat, untuk menemukan konsep atau teori yang terkandung di dalamnya. Studi kepustakaan dilakukan dengan beberapa langkah berikut: (1) identifikasi permasalahan, (2) landasan teori, (3) penetapan maksud penelitian, (4) pengumpulan data, dan (5) analisis dan interpretasi data. Adapun data yang digunakan adalah data sekunder yaitu dengan menganalisis laporan dari Travel and Tourism Competitiveness Index yang dikeluarkan oleh World Economic Forum setiap dua tahun sekali.

\section{HASIL DAN PEMBAHASAN}

\section{A. Perubahan Paradigma Teori Daya Saing}

Teori daya saing telah mengalami evolusi menjadi sebuah paradigma baru. Awalnya, teori daya saing membahas mengenai kemampuan suatu perusahaan agar tetap bertahan dalam pasar yang dinamis. Sesuai dengan teori Kuhn dalam teori perkembangan ilmu pengetahuan, yang mengatakan bahwa sebuah teori akan mengalami suatu revolusi menjadi suatu paradigma baru yang akan menjadi sebuah normal science, maka begitu pula dengan teori daya saing ini. Teori daya saing ini mengalami perkembangan dalam pendefinisian menjadi suatu konsep daya saing antar negara. Pada dasarnya secara umum daya saing didefinisikan sebagai kemampuan dari suatu industri untuk menunjukkan keunggulan dalam hal tertentu, dengan cara memperlihatkan situasi dan kondisi yang paling menguntungkan, hasil kerja yang lebih baik dibandingkan dengan industri lainnya.

Faktor yang harus diperhatikan dalam persaingan adalah keunggulan. Menurut Heckscher-Ohlin (1990), Faktor produksi yang diumumnya dikategorikan sebagai tanah, tenaga kerja dan modal, terlalu umum untuk dapat menunjukkan keunggulan daya saing dalam strategi industri-industri yang berbeda. Faktor-faktor 
dapat dikelompokkan ke dalam sejumlah kategori besar seperti SDM, fisik, ilmu pengetahuan, modal dan infrastruktur. Keunggulan daya saing dari faktor-faktor tergantung pada bagaimana efisiensi dan efektifitas faktor-faktor tersebut menyebar. Teknologi dapat digunakan sebagai salah satu alat yang digunakan faktor-faktor daya saing untuk meningkatkan produktivitas. Faktor-faktor dikembangkan dalam suatu perekonomian menjadi sangat penting, karena kecanggihan teknologi dan sumber daya manusia yang berkemampuan dapat digunakan pada suatu keragaman industri. Ketersediaan faktor-faktor tersebut belum cukup untuk menjelaskan keberhasilan daya saing. Suatu perusahaan mendapatkan keunggulan daya saing jika memiliki biaya rendah dan faktor-faktor tersebut mempunyai kualitas yang tinggi. Teori ini menekankan bahwa faktor endowment (faktor sumber daya yang melimpah) yang berbeda dapat menjelaskan mengapa negara-negara memiliki keunggulan pada komoditas yang berbeda. Dalam hal ini terdapat dua intensitas faktor, yaitu labor-intensive atau faktor capital-intensive. Intensitas faktor tersebut tergantung pada tingkat teknologi. Teorema ini mengatakan bahwa suatu negara yang berlimpah modal akan mengekspor barang capital-intensive di mana negara yang melimpah tenaga kerja akan mengekspor barang labor-intensive. Perputaran perdagangan akan naik sampai harga kedua barang akan sama pada kedua pasar tersebut.

Teori daya saing lainnya adalah teori keunggulan daya saing Porter. Menurut Porter (2000), keunggulan komparatif dapat ditemukan pada tingkat perusahaan dan pada tingkat nasional. Ada empat hal dalam membangun keunggulan dari suatu negara digambarkan oleh Porter sebagai suatu skema berbentuk berlian, yaitu kondisi faktor seperti tenaga terampil dan sarana prasarana, kondisi permintaan dan tuntutan mutu dalam negeri untuk hasil industri tertentu, eksistensi industri terkait dan pendukung yang berdaya saing, serta strategi, struktur dan persaingan antar perusahaan. Selain itu terdapat korelasi yang cukup signifikan dengan variabel peran pemerintah untuk menciptakan keunggulan daya saing nasional dan adanya faktor kebetulan (penemuan baru, melonjaknya harga, perubahan kurs dan konflik keamanan antar negara). Semakin tinggi tingkat persaingan antar perusahaan di suatu negara, maka semakin tinggi pula tingkat daya saing internasionalnya. Tujuan atas aspek perubahan fundamental yang dibuat oleh Porter sekaligus membedakan rumusan teorinya dari kelimpahan faktor-faktor produksi yang dimiliki, ada yang bersifat dasar seperti daya fisik yang belum terolah atau tenaga kerja non-terampil, serta bersifat lanjutan yang berbagai faktor produksinya sudah canggih seperti peralatan model, tenaga kerja yang memiliki kemampuan pengetahuan serta keterampilan tinggi, sumber-sumber daya pengetahuan serta riset yang diperoleh dari lembaga ilmiah. Faktor pemilihan kompetitif tergantung pada keunggulan suatu komoditas yang dihasilkan oleh perusahaan atau industri. Selain itu tergantung pada permintaan konsumen akan produk yang cukup signifikan mendorong perusahaan untuk lebih kompetitif. Berdasarkan hal tersebut, pola perdagangan saat ini dengan daya saing suatu komoditas tidak hanya melihat pendekatan pasar namun melakukan strategi dalam perdagangan internasional. Pendekatan yang digunakan saat ini adalah resource based strategy dimana faktor sumber daya menjadi lebih penting.

Teorema daya saing yang juga mengandalkan keunggulan kompetitif pada perkembangannya adalah teorema Thurow. Menurut Thurow (2001) dalam era globalisasi ekonomi, keunggulan kompetitif menjadi faktor yang tidak bisa 
diabaikan karena dalam konteks daya saing komoditas yang akan diperdagangkan memiliki keunguulan komparatif dari segi kelimpahan faktor tetapi belum kompetitif. Menurut Thurow (2001) bahwa suatu konsep keunggulan komparatif akan bergeser memperhitungkan teknologi sebagai unsur dinamis, hal ini disebabkan karena penguasaan ilmu pengetahuan dan teknologi telah mampu menghasilkan peralatan canggih untuk menggeser sebagian besar tenaga kerja manusia sehingga rasio modal dan tenaga kerja bukan lagi menjadi variabelvariabel penting, walaupun tenaga kerja tetap dibutuhkan namun perananya menjadi sangat kurang dalam proses produksi. Menurut Tambunan (2002) bahwa daya saing suatu komoditas juga ditentukan oleh teknologinya. Di masa depan tuntutan teknologi merupakan karakteristik dalam proses pengembangan ekspor dengan mengambil dasar pemikiran dan asumsi-asumsi yang dibangun oleh teori klasik. Akan tetapi teori-teori klasik tidak melihat pentingnya pengaruh proses teknologi terhadap pola perdagangan dunia. Karena pada akhirnya keunggulan kompetitif akan lebih menentukan daya suatu negara atau suatu komoditas daripada keunggulan komparatifnya. Menurut Tambunan (2002) kondisi utama yang harus dipenuhi agar pengembangan industri pada akhirnya dapat bersaing di pasar regional maupun internasional adalah:

1. Menciptakan lingkungan internal yang kondusif Meliputi kualitas sumber daya manusia, penguasaan teknologi dan informasi, struktur organisasi, sistem manajemen, budaya bisnis, kekuatan modal dan jaringan bisnis dengan pihak luar.

2. Menciptakan lingkungan eksternal yang kondusif Meliputi sistem perburuhan dan kondisi pasar buruh, kondisi infrastruktur dan tingkat pendidikan masyarakat

Sedangkan menurut Ismail dan Syafitri (2005), untuk mengukur daya saing ekonomi daerah, ada empat indikator yang harus digunakan yaitu:

1. Struktur ekonomi yang meliputi kondisi ekonomi, produktivitas, output dan nilai tambah, serta tingkat investasi asing atau domestik.

2. Potensi wilayah yang meliputi nontradeable seperti lokasi, prasarana, sumber daya alam, serta citra daerah.

3. Sumber daya manusia meliputi kualitas sumberdaya manusia yang mendukung kegiatan ekonomi mulai dari proses produksi, konsumsi, hingga distribusi.

4. Kelembagaan meliputi konsistensi kebijakan pemerintah dan perilaku masyarakat yang pro-pengembangan ekonomi lokal, serta budaya yang mendukung produktivitas.

World Economic Forum (WEF), suatu lembaga yang menerbitkan "Global Competitiveness Report" mendefenisikan daya saing nasional secara lebih luas maknanya dengan kalimat yang sangat sederhana. WEF mendefenisikan daya saing nasional sebagai "kemampuan perekonomian nasional untuk mencapai pertumbuhan ekonomi yang tinggi dan berkelanjutan”. Fokusnya adalah pada kebijakan-kebijakan yang tepat, institusi-institusi yang sesuai, serta karakteristikkarakteristik ekonomi lain yang mendukung terwujudnya pertumbuhan ekonomi yang tinggi dan berkelanjutan (Abdullah, 2002). 


\section{B. Kajian 14 Pilar pada TTCI sebagai Indikator Daya Saing Suatu Negara}

Hasil penelitian ini berupa sebuah kajian mengenai 14 pilar pada Travel and Tourism Competitiveness Index (TTCI) sebagai indikator daya saing suatu negara. Tabel 1 adalah hasil kajian ke-14 pilar yang digunakan sebagai indikator daya saing suatu negara. Pilar-pilar yang dimaksud ini diantaranya adalah business environment, safety and security, health and hygiene, human resource and labour market, ICT readiness, prioritization of travel and tourism, international openness, price competitiveness, environmental sustainability, air transport infrastructure, ground and port infrastructure, tourist service infrastructure, natural resources, dan cultural resources and business travel. 
Table 1. Peran Indikator Daya Saing pada 14 Pilar Travel and Tourism Competitiveness Index

\begin{tabular}{|c|c|c|c|c|}
\hline No & Sub Index & Pillar & Sub Pillar & Analisis Kajian \\
\hline & \multirow[t]{2}{*}{$\begin{array}{c}\text { Enabling } \\
\text { Environment }\end{array}$} & $\begin{array}{l}\text { Business } \\
\text { Environment }\end{array}$ & $\begin{array}{l}\text { 1) Property rights } \\
\text { 2) Impact of rules on FDI } \\
\text { 3) Efficiency of legal framework in } \\
\text { settling disputes } \\
\text { 4) Efficiency of legal framework in } \\
\text { challenging regulations } \\
\text { 5) Time required to deal with } \\
\text { construction permits } \\
\text { 6) Cost to deal with construction } \\
\text { permits } \\
\text { 7) Extent of market dominance } \\
\text { 8) Time required to start a business } \\
\text { 9) Cost to start a business } \\
\text { 10) Extent and effect of taxation on } \\
\text { incentives to work1 } \\
\text { 11) Extent and effect of taxation on } \\
\text { incentives to invest } 1 \\
\text { 12) Total tax rate }\end{array}$ & 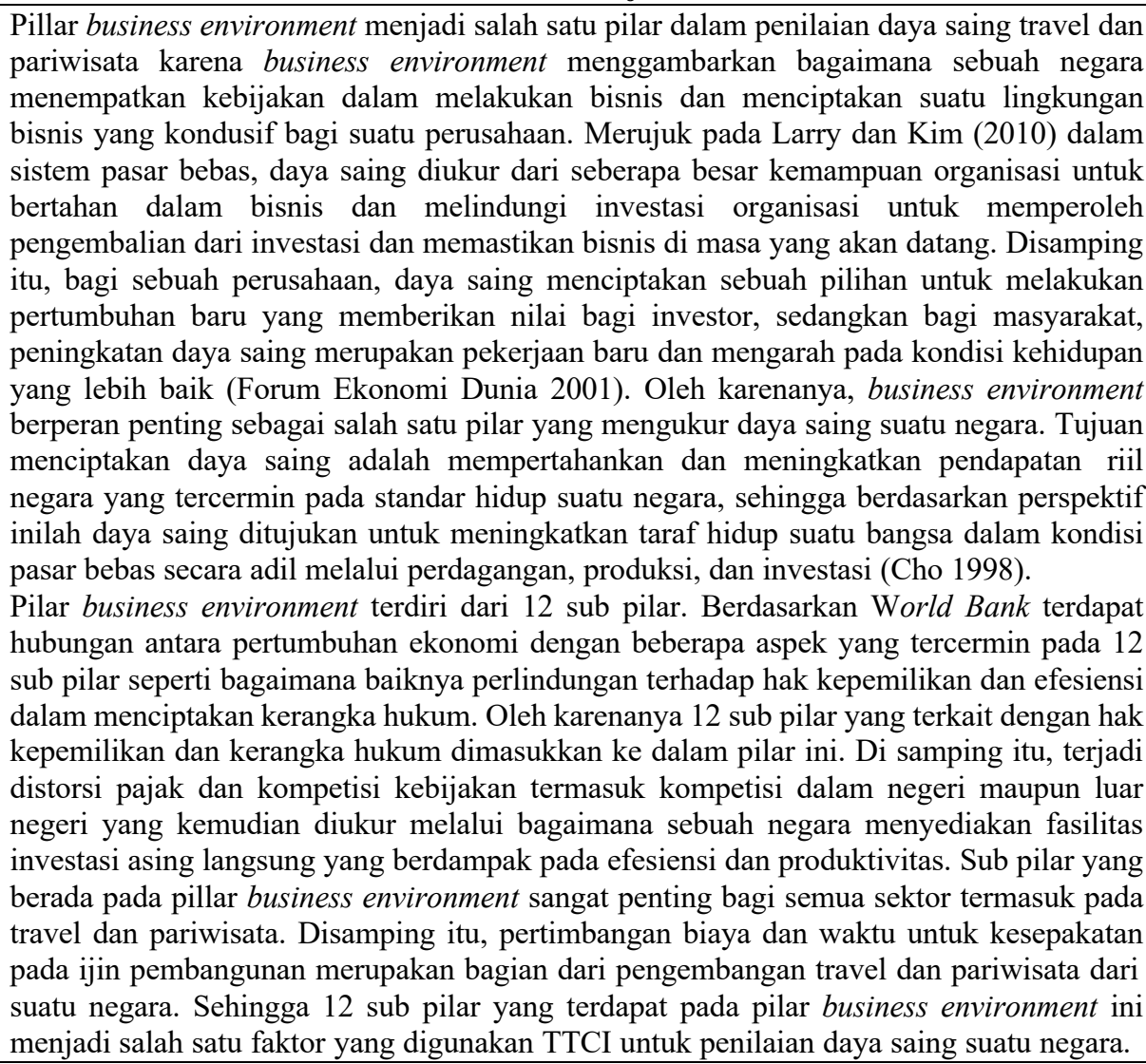 \\
\hline & & Safety and Security & $\begin{array}{l}\text { 1) Business costs of crime and } \\
\text { violence } \\
\text { 2) Reliability of police services } \\
\text { 3) Business costs of terrorism } \\
\text { 4) Index of terrorism incidence } \\
\text { 5) Homicide rate }\end{array}$ & $\begin{array}{l}\text { Pilar safety dan security yang terdiri dari } 5 \text { sub pilar menggambarkan bahwa keselamatan } \\
\text { dan keamanan adalah faktor penting yang menentukan daya saing industri travel dan } \\
\text { pariwisata suatu negara. Pada konteks pariwisata, pengukuran daya saing melibatkan suatu } \\
\text { realitas situasi yang didasarkan pada objektivitas daya saing seperti daya saing harga, } \\
\text { tingkat kejahatan yang melibatkan wisatawan sebagai korban, dan perspektif wisatawan. } \\
\text { Persepktif wisatawan yang salah satunya adalah tingkat keselamatan dan keamanan } \\
\text { dijadikan suatu ukuran daya saing dalam menentukan model daya saing pariwisata (World }\end{array}$ \\
\hline
\end{tabular}




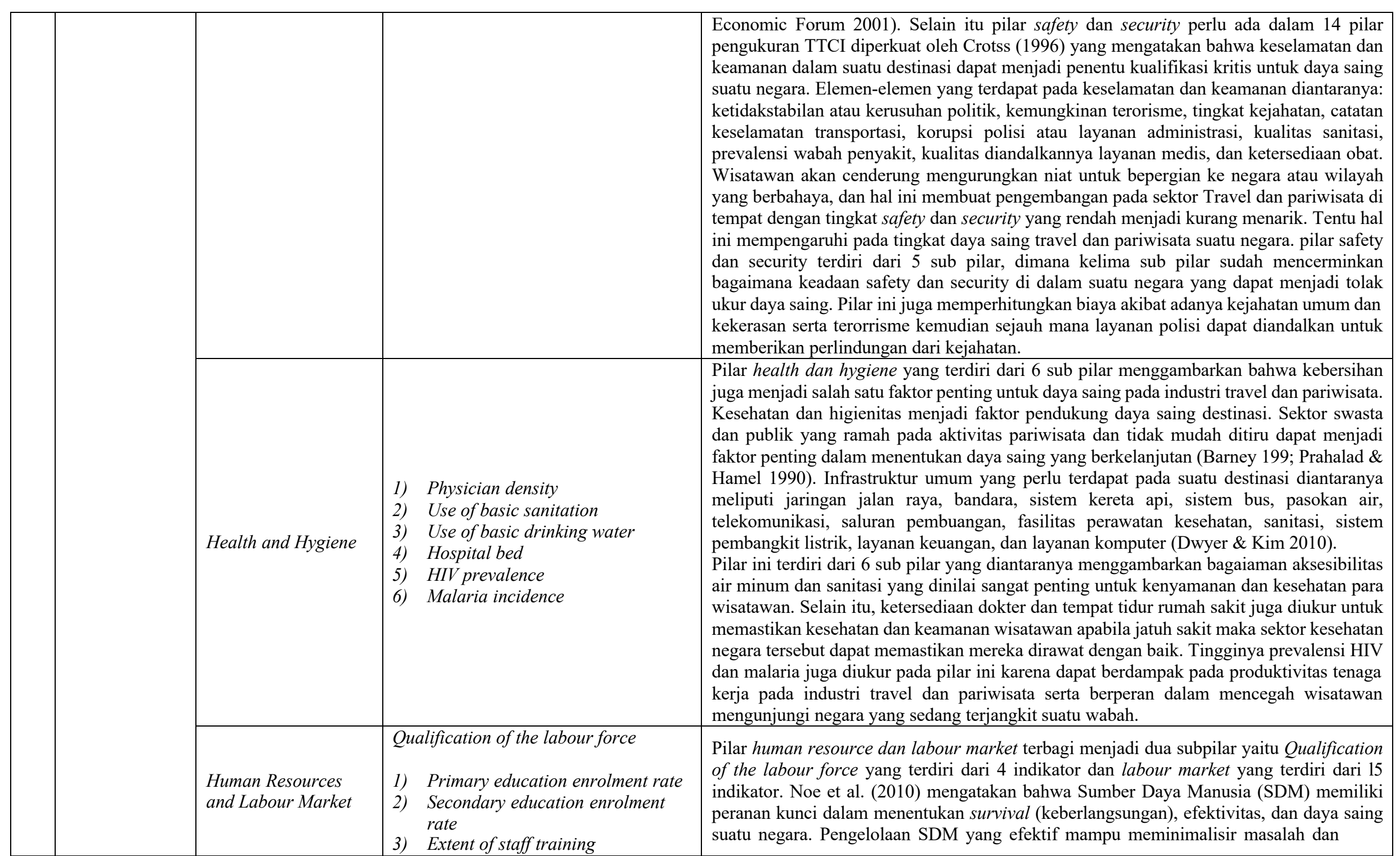




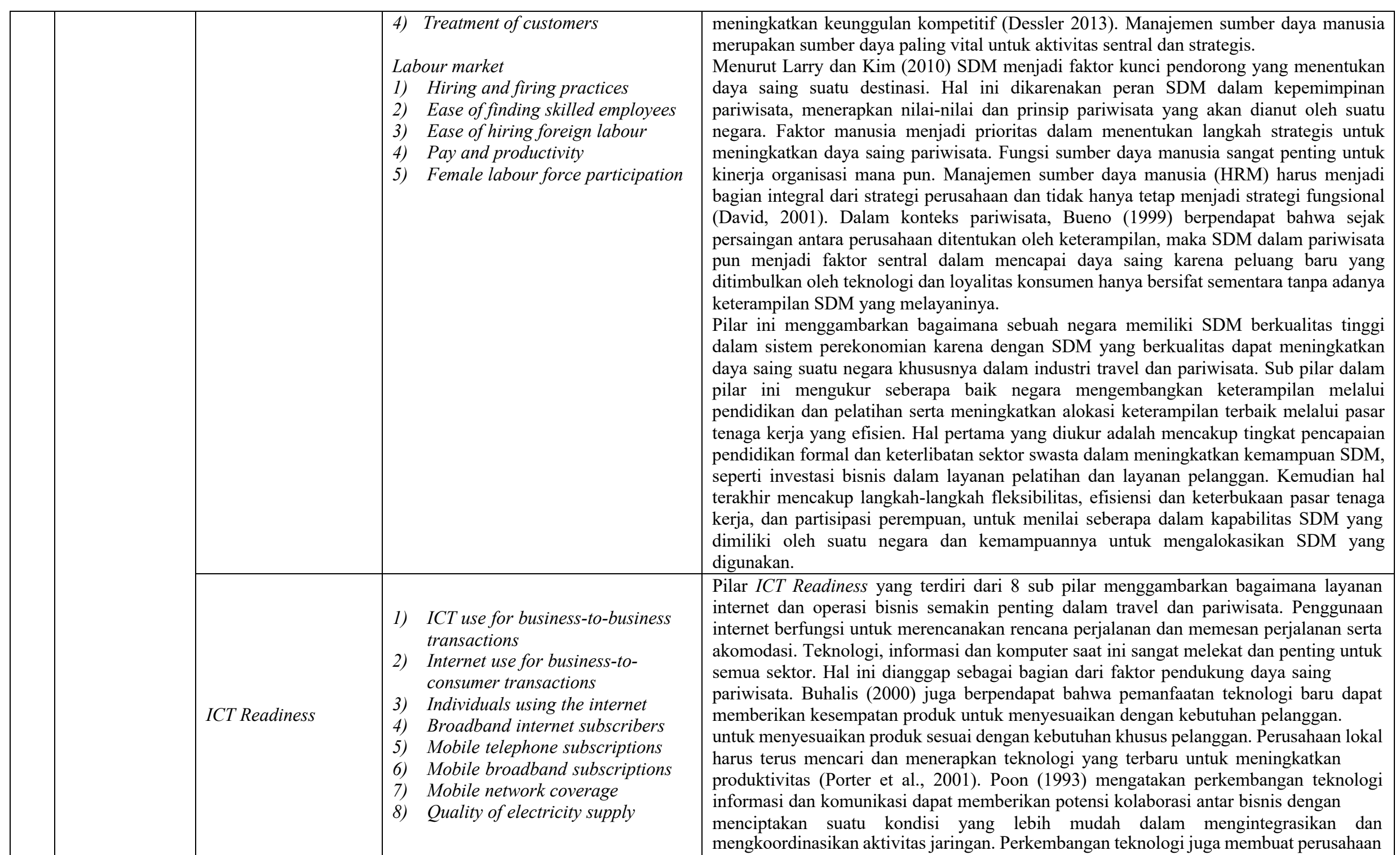




\begin{tabular}{|c|c|c|c|c|}
\hline & & & & $\begin{array}{l}\text { dapat melakukan pengembangan virtual sehingga memberikan dampak pada peningkatan } \\
\text { daya saing yang kompetiti(fEvans et al., 2003.) } \\
\text { Sub pilar pada pilar ini mengukur tidak hanya keberadaan infrastruktur dan perangkat } \\
\text { keras modern (yaitu jangkauan jaringan seluler dan kualitas pasokan listrik), tetapi juga } \\
\text { kapasitas bisnis dan individu untuk menggunakan dan tersedianya layanan online. }\end{array}$ \\
\hline & $\begin{array}{l}T \& T \text { Policy } \\
\text { and Enabling } \\
\text { Conditions }\end{array}$ & $\begin{array}{l}\text { International } \\
\text { Openness }\end{array}$ & $\begin{array}{l}\text { 1) Visa requirements } \\
\text { 2) Openness of bilateral Air Service } \\
\text { Agreements } \\
\text { 3) Number of regional trade } \\
\text { agreements in force }\end{array}$ & $\begin{array}{l}\text { Pilar international openness dengan } 3 \text { sub pilar menggambarkan bagaimana suatu negara } \\
\text { mengembangkan sektor travel dan pariwisata yang kompetitif secara internasional. Daya } \\
\text { saing suatu destinasi wisata dikaitkan dengan kemakmuran ekonomi penduduk suatu } \\
\text { negara (Buhalis 2000; Crouch \& Ritchie 1999). Pembangunan pada suatu negara } \\
\text { dirancang untuk menarik minat wisatawan internasional yang memiliki berbagai tujuan. }\end{array}$ \\
\hline
\end{tabular}




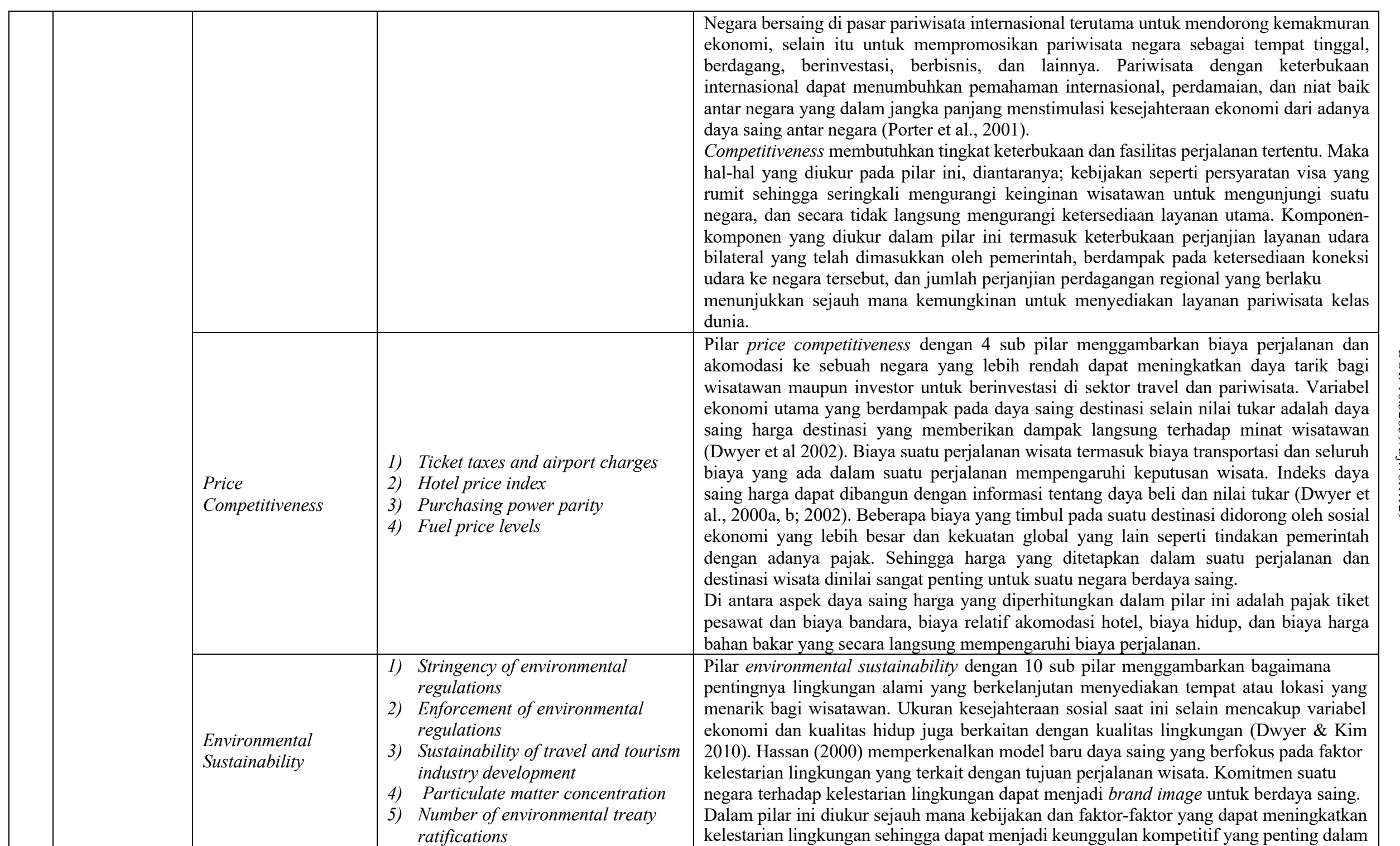



6) Baseline water stress
7) Threatened species
8) Forest cover change
9) Wastewater treatment
10) Fish stock status

\section{1) Quality of air transport} infrastructure

2) Available seat kilometres, domestic

Air Transport $\quad 3)$ Available seat kilometres,

Infrastructure international

4) Aircraft departures

5) Airport density

6) Number of operating airlines
Infrastructure

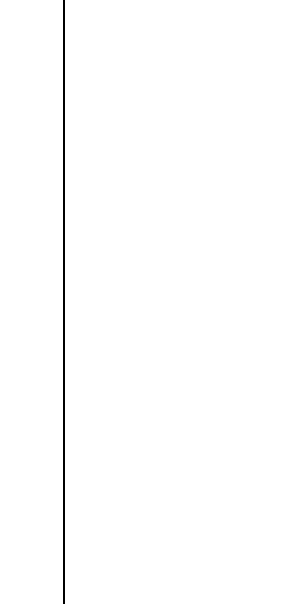

1) Quality of roads

2) Road density

3) Paved road density

Ground and Port Infrastructure

Tourist Service Infrastructure
4) Quality of railroad infrastructure

5) Railroad density

6) Quality of port infrastructure

7) Ground transport efficiency

1) Hotel rooms

2) Quality of tourism infrastructure

3) Presence of major car rental companies memastikan daya tarik di masa yang akan datang. Pilar ini terdiri dari sub pilar kebijakan seperti ketatnya penegakan peraturan pemerintah mengenai lingkungan dan menilai variabel status air, sumber daya hutan dan kehidupan laut melalui pendekatan status stok ikan. Mengingat dampak lingkungan dari pariwisata itu sendiri, diperhitungkan pula sejauh mana industri travel dan pariwisata dikembangkan secara berkelanjutan.

Pilar air transport infrastructure dengan 6 sub pilar menggambarkan bagaimana konektivitas udara suatu negara sangat penting untuk kemudahan akses wisatawan ke dan dari negara, serta pergerakan di banyak negara. Merujuk pada Zhang, Zheng, dan Lu (2018) Keterbukaan perjanjian layanan udara menggunakan satu atau beberapa indikator untuk menunjukkan perjanjian layanan udara terbuka dan tidak terbuka. Sejarah perkembangan kebijakan transportasi udara internasional menunjukkan bahwa keterbukaan layanan udara merupakan proses evolusioner yang dapat menjadi daya saing suatu negara. Moe et al (1993) mengatakan bahwa infrastruktur transportasi merupakan faktor terpenting setelah faktor lingkungan untuk memberikan pengalaman terutama pada wisatawan internasional dengan tujuan tertentu.

Dalam pilar ini diukur pula jumlah transportasi udara seperti ketersediaan kursi per kilometer, jumlah keberangkatan, kepadatan bandara dan jumlah maskapai penerbangan yang beroperasi, serta kualitas infrastruktur transportasi udara untuk penerbangan domestik dan internasional

Pilar ground and port infrastructure yang terdiri dari 7 sub pilar menggambarkan ketersediaan transportasi yang efisien dan mudah diakses ke pusat-pusat bisnis utama dan tempat-tempat wisata, sangat penting untuk sektor travel dan pariwisata di sebuah negara. Porter (1990) mengatakan bahwa pentingnya sumberdaya yang diciptakan atau dibangun untuk memudahkan akses menuju kepada tempat wisata, hal ini dapat menentukan daya saing pariwisata suatu negara, seperti infrastruktur pariwisata, tempat hiburan, pusa perbelanjaan dan restaurant. Murphy et al (2000) menemukan fakta bahwa kurangnya infrastruktur penunjang wisata mempengaruhi pengalaman wisata seseorang dan infrastruktur pariwisata merupakan prediktor penting dari kualitas dan nilai perjalanan yang dirasakan.

Pilar ini menggambarkan bagaimana konektivitas dan integrasi trasnportasi yang luas seperti kepadatan jalan dan kereta api, infrastruktur jalan, rel kereta api, dan pelabuhan yang memenuhi standar kenyamanan, keamanan dan efisiensi modal internasional. Pilar ini juga menjelaskan jalan yang tidak beraspal memungkinkan akses ke penduduk loka dan sampai batas tertentu dapat mewakili keberadaan sebuah jalan dengan menyajikan keindahan alam yang dapat menarik wisatawan.

Pilar tourist service infrastructure dengan empat sub pilar menggambarkan ketersediaan akomodasi, resort dan fasilitas hiburan berkualitas yang memadai dapat mewakili keunggulan kompetitif yang signifikan bagi suatu negara. Dwyer \& Kim (2010) mengatakan bahwa pariwisata bergantung pada penyediaan berbagai layanan tambahan. 


\begin{tabular}{|c|c|c|c|c|}
\hline & & & $\begin{array}{l}\text { 4) Automated teller machines per } \\
\text { adult population }\end{array}$ & $\begin{array}{l}\text { Infrastruktur layanan yang dimaksud terkait fasilitas perbelanjaan ritel, toko makanan, } \\
\text { bengkel (perawatan mobil, pompa bensin), apotek, toko buku, binatu, penata rambut, } \\
\text { kantor administrasi. Suatu destinasi wisata dapat berfungsi dengan baik dan lebih efektif } \\
\text { apabila terdapat banyak layanan yang tersedia bagi wisatawan sehingga hal ini dapat pula } \\
\text { meningkatkan daya saing (Porter 2000). } \\
\text { Pilar ini menggambarkan bagaimana infrastruktur layanan pariwisata dilakukan melalui } \\
\text { jumlah kamar hotel yang dilengkapi dengan tingkat akses ke layanan seperti penyewaan } \\
\text { mobil dan ATM. }\end{array}$ \\
\hline \multirow[t]{2}{*}{4} & \multirow{2}{*}{$\begin{array}{l}\text { Natural and } \\
\text { Cultural } \\
\text { Resource }\end{array}$} & Natural Resources & $\begin{array}{l}\text { 1) Number of World Heritage natural } \\
\text { sites } \\
\text { 2) Total known species } \\
\text { 3) Total protected areas } \\
\text { 4) Natural tourism digital demand } \\
\text { 5) Attractiveness of natural assets }\end{array}$ & $\begin{array}{l}\text { Pilar natural resources dengan } 5 \text { sub pilar menggambarkan negara-negara dengan aset } \\
\text { alam jelas memiliki keunggulan kompetitif dalam menarik wisatawan. Sementara Porter } \\
\text { (2000) lebih menekankan penciptaan faktor sebagai sumberdaya keunggulan kompetitif, } \\
\text { Buckley (1994), Dunn \& Iso-Ahola (1991) mengatakan bahwa sumber daya alam yang } \\
\text { memang sudah dimiliki suatu negara dalam bentuk pariwisata dapat memberikan kepuasan } \\
\text { pada wisatawan. Pada konteks pariwisata, sumber daya alam memiliki kapasitas yang } \\
\text { besar untuk menarik pengunjung, terlepas dari 'nilai tambah' yang diberikan oleh penyedia } \\
\text { layanan (Dwyer \& Kim 2010). } \\
\text { Pilar ini menggambarkan beberapa penilaian terhadap daya tarik suatu destinasi, termasuk } \\
\text { jumlah situs warisan Dunia UNESCO yang alami, ukuran kualitas lingkungan alam yang } \\
\text { mewakili keindahan bentang alamnya, kekayaan fauna di negara tersebut yang diukur } \\
\text { dengan total spesies hewan yang diketahui, dan persentase kawasan yang dilindungi secara } \\
\text { nasional yang mewakili luas taman nasional dan cagar alam. }\end{array}$ \\
\hline & & $\begin{array}{l}\text { Cultural Resources } \\
\text { and Business Travel }\end{array}$ & $\begin{array}{l}\text { 1) Number of World Heritage cultural } \\
\text { sites } \\
\text { 2) Number of oral and intangible } \\
\text { cultural heritage expressions } \\
\text { 3) Number of sports stadiums } \\
\text { 4) Number of international } \\
\text { association meetings } \\
\text { 5) Cultural and entertainment tourism } \\
\text { digital demand }\end{array}$ & $\begin{array}{l}\text { Pilar cultural resources and business travel dengan } 5 \text { indikator menggambarkan sumber } \\
\text { daya budaya suatu negara adalah pendorong penting daya saing travel dan pariwisata } \\
\text { lainnya. Ritchie \& Zins (1978) mengatakan bahwa dimensi budaya dapat meningkatkan } \\
\text { daya tarik suatu tujuan wisata. Pengelolaan sumberdaya ekologi, sosial, dan budaya yang } \\
\text { baik dapat menstimulasi daya saing yang berkelanjutan bagi suatu negara (Dwyer \& Kim } \\
\text { 2010). } \\
\text { Pilar ini menggambarkan berapa jumlah situs budaya Warisan Dunia UNESCO, jumlah } \\
\text { stadion besar yang dapat menjadi tuan rumah acara olahraga atau hiburan yang signifikan, } \\
\text { dan permintaan budaya dan hiburan secara digital, jumlah pencarian online terkait dengan } \\
\text { budaya suatu negara. Sumber daya yang dimiliki sebuah negara dapat meningkatkan minat } \\
\text { kunjungan wisatawan untuk datang ke negara tersebut. Jumlah pertemuan asosiasi } \\
\text { internasional yang ada di suatu negara juga diperhitungkan sebagai perjalanan bisnis. }\end{array}$ \\
\hline
\end{tabular}




\section{SIMPULAN}

Berdasarkan hasil analisis yang telah dilakukan pada ke-14 pilar pada Travel and Tourism Competitiveness Index (TTCI), sub pilar yang terdapat pada masing-masing pilar sebagai indikator untuk mengukur daya saing suatu negara dalam travel dan pariwisata cukup mewakili indikator daya saing. Namun, hanya saja untuk beberapa negara, khususnya negara berkembang masih terdapat beberapa sub pilar yang dirasa masih kurang tepat sebagai indikator pengukuran daya saing. Hal ini dikarenakan, negara beberapa negara berkembang masih dalam tahap proses pembangunan, seperti pembangunan infrastruktur, perbaikan sistem, pengembangan teknologi, pembenahan penanganan limbah, sanitasi, dan fasilitas lainnya. Hal inilah yang mengakibatkan nilai yang diperoleh negara berkembang pastinya sudah pasti akan lebih rendah dibandingkan negara maju. Namun di samping itu, indikator ini juga dapat menstimulasi negara-negara berkembang untuk terus mengejar ketertinggalannya dan mengubah statusnya menjadi negara maju dan memiliki daya saing yang tinggi khususnya dalam sektor travel dan pariwisata.

\section{DAFTAR PUSTAKA}

Abdullah, M. Faisal. (2002). Dasar-Dasar Manajemen Keuangan, UMM Press, Yogyakarta (ID): UMM Press.

Barney, J.B. (1991). Firms resources and sustained competitive advantage. Journal of Management 17, 99-120.

Brokaj, R., (2014). Local Government's Role in The Sustainable Tourism Development of a Destination. European Scientific Journal, 10(31).

Buckley, R. (1994). A framework for ecotourism. Annals of Tourism Research 21 (3), 661-9.

Bueno, A. (1999). Competitiveness in the tourist industry and the role of the Spanish public administration. Turizam47 (4),316-31. Special issue on competitiveness in tourism and hospitality.

Buhalis, D. (2000). Marketing the competitive destination in the future. Tourism Management 21 (1), 97-116.

Cho, D.S. (1998). From national competitiveness to bloc and global competitiveness. Competitiveness Review 8 (1).

Crotts, J. (1996). Theoretical perspectives on tourist criminal victimisation. Journal of Tourism Studies 7 (1), 2-9.

Crouch, G.I and Ritchie, J.R.B. (1999). Tourism, competitiveness, and societal prosperity. Journal of Business Research 44, 137-52.

David, F. (2001). StrategicManagement:Concepts (8thedn). Upper Saddle River, NJ: Prentice Hall.

David, Richardo, 2008. Teori Pertumbuhan Klasik. Jakarta (ID): PT. Raja Grafindo Pustaka.

Dessler. (2013). Manajemen Sumber Daya Manusia Human Reources, Jilid 2. Jakarta: Prenhalindo.

Dunn, R. and Iso-Ahala, S. (1991) Sightseeing tourists' motivations and satisfaction. Annals of Tourism Research 18 (2), 226-37. 
Dwyer, L., Forsyth, P. and Rao,P. (2000a)The price competitiveness of travel and tourism: A comparison of 19 destinations. Tourism Management 21 (1), 922.

Dwyer, L., Forsyth, P. and Rao, P. (2000b) Sectoral analysis of price competitiveness of tourism: An international comparison. Tourism Analysis $5(1), 1-12$.

Dwyer, L., Forsyth, P. and Rao, P. (2002). Destination price competitiveness: Exchange rate changes vs inflation rates. Journal of Travel Research 40 (February), 340-48.

Dwyer, Larry dan Kim, Chulwon. 2010. Destination Competitiveness: Determinants and Indicators. Current Issuen in Tourism, Vol: (6)5, 369-414, DOI: $10.1080 / 13683500308667962$

Evans, N., Campbell, D. and Stonehouse, G. (2003) Strategic Management for Travel and Tourism. Oxford: Butterworth-Heinemann.

Frinces, Z. Heflin. (2011). Be An Entreprenuer, Jadilah Seorang Wirausaha. Yogyakarta: Graha Ilmu

Hassan, S. (2000) Determinants of market competitiveness in an environmentally sustainable tourism industry. Journal of Travel Research 38 (3) (February), 239-45.

Heath, E. (2000) Key trends and challenges in destination marketing: The need for a new paradigm. In J. Ruddy and S. Flanagan (eds) Tourism DestinationMarketing:Gaining the Competitive Edge (pp. 123-35). Tourism Research Centre, Dublin Institute of Technology.

Ibrahim. (2015). Metodologi Penelitian Kualitatif. Bandung: Alfabeta.

Ismail, M. dan Wildan Syafitri. (2005). Model Pengembangan Agroindustri Unggulan Untuk Memperkuat Daya Saing Daerah. TEMA. Volume 6, Nomer 1 Maret 2005.

Mo, C., Handy, D. and Havitz, M. (1993) Testing an international tourist role typology. Annals of Tourism Research 20 (2), 319-35

Murphy P., Pritchard, M. and Smith, B. (2000) The destination product and its impact on traveller perceptions. Tourism Management 21 (1), 43-52.

Nizar, M. A. (2011). Pengaruh Pariwisata Terhadap Pertumbuhan Ekonomi Di Indonesia Daftar Pustaka. Munich Personal RePEc Archive.

Noe Raymond et al. (2006). Human Resource Management 5 th edition. Mc Graw Hill

Ohlin, B. (1933). Interregional and intermltional trade (Harvard University Press, Cambridge).

Poon, A. (1993) Tourism, Technology, and Competitive Strategy. Wallingford: CAB International.

Porter, M.E. (1990). The Competitive Advantage of Nations. New York: Free Press.

Porter, Michael E. (1995). Competitive Advantage. New York (NY): The Free Press., edisi terjemahan 2008: Kharisma Publishing Group.

Porter, Michael E. (2001). Strategi Bersaing, Teknik Menganalisis Industri dan Pesaing. Jakarta: Erlangga.

Porter, Michael E. (2002). Strategi Bersaing Teknis Menganalisis Industri dan Pesaing, Penerbit Erlangga, Jakarta

Prahalad, C.K. and Hamel, G. (1990). The core competence of the corporation. Harvard Business Review (May-June), 79-91. 
Ritchie, B.R. and Zins,M. (1978). Culture as a determinant of the attractiveness of a tourism region. Annals of Tourism Research 5, 252-67.

Smith, S. (1994) The tourist product. Annals of Tourism Research 21 (3), 582-95. Tambunan, Tulus. (2002). Usaha Kecil dan Menengah di Indonesia : Beberapa Isu Penting. Jakarta: Salemba Empat

Thurow, Lester C. (1999). Building Wealth: The New Rules of Individuals, Companies and Nations in a Knowledge Based Economy. New York (NY): Harper Collins Publisher, Inc.

UNWTO. (2017). Tourism Highlights 2017 Edition. Diunduh 18 November 2019, from World Tourism Organization Website: www.wto.org

World Economic Forum. (2001) The Global Competitiveness Report 2001-2002.

World Economic Forum. (2019). Travel and Tourism Competitiveness Index Report. Diunduh 20 November 2019, from World Tourism Organization Website: www.wto.org

Zhang, Yi., Zheng, Xingwu., dan Lu Wei. (2018). Measuring The Openness of Chinese International Air Transport Policy. Transport Policy Journal. https://doi.org/10.1016/j.tranpol.2018.03.014 